\title{
Preparing Health Professions Students for \\ Terrorism, Disaster, and Public Health \\ Emergencies: Core Competencies
}

David Markenson, MD, EMT-P, Charles DiMaggio, PhD, MPH, PA-C, and

Irwin Redlener, MD

\section{Abstract}

The recent increased threat of terrorism, coupled with the ever-present dangers posed by natural disasters and public health emergencies, clearly support the need to incorporate bioterrorism preparedness and emergency response material into the curricula of every health professions school in the nation. A main barrier to health care preparedness in this country is a lack of coordination across the spectrum of public health and health care communities and disciplines. Ensuring a unified and coordinated approach to preparedness requires that benchmarks and standards be consistent across health care disciplines and public health, with the most basic level being education of health professions students.

Educational competencies establish the foundation that enables graduates to meet occupational competencies. However, educational needs for students differ from the needs of practitioners. In addition, there must be a clear connection between departments of public health and all other health care entities to ensure proper preparedness.

The authors describe both a process and a list of core competencies for teaching emergency preparedness to students in the health care professions, developed in 2003 and 2004 by a team of experts from the four health professions schools of Columbia University in New York City. These competencies are directly applicable to medical, dental, nursing. and public health students. They can also easily be adapted to other health care disciplines, so long as differences in levels of proficiency and the need for clinical competency are taken into consideration.

Acad Med. 2005; 80:517-526. he current increased threats of terrorism, and other findings discussed below, clearly support the need to incorporate terrorism preparedness and response material into the curricula for every health professions school in the nation. In this article, we describe a process and present a list of core competencies for terrorism preparedness.

\footnotetext{
Dr. Markenson is deputy director, National Center for Disaster Preparedness; director, Program for Pediatric Preparedness; and assistant professor of population and family health, Columbia University Mailman School of Public Health. He is also assistant professor of pediatrics, Columbia University College of Physicians and Surgeons, New York, New York.
}

Dr. DiMaggio is director, Program for Healthcare System Preparedness, National Center for Disaster Preparedness; and assistant professor of clinical epidemiology, Columbia University Mailman School of Public Health, New York, New York.

Dr. Redlener is director, National Center for Disaster Preparedness, and Clinical Professor of Pediatrics and Public Health, Columbia University School of Public Health, New York, New York.

Correspondence should be addressed to Dr. Markenson, National Center for Disaster

Preparedness, Columbia University Mailman School of Public Health, 722 West 168th Street, 10th Floor, New York, NY 10032; telephone: (212) 342-0408; fax: (212) 342-5160; e-mail: 〈Dsm2002@columbia.edu〉.

\section{Introduction}

Health care workers are the second largest workforce in the United States, second only to the U.S. military. In 2003, there were nearly 2.43 million registered nurses, 700,000 physicians, 350,000 dentists, and 450,000 public health workers, as well as many students enrolled in hundreds of different professions school programs. ' It is essential for these health professionals to be appropriately and adequately prepared to respond to terrorism and other public health emergencies. However, the sparse data available suggest that health professionals do not currently feel competent or knowledgeable in this area, although they would like to be.

\section{The need}

Soon after the 2001 anthrax attacks, the Columbia University Center for Public Health Preparedness developed and conducted a series of bioterrorism educational programs. ${ }^{2}$ A majority (77.4\%) of the 377 participating clinicians reported having concerns about future bioterrorism attacks. They also reported that their patients shared these concerns, with approximately $90 \%$ of clinicians reporting that they had cared for patients with complaints related to a fear of bioterrorism during the two months before the training program. Perhaps most important, many clinicians reported feeling ill equipped to deal with such concerns. Data also revealed that the clinicians' levels of knowledge of bioterrorism were similar, regardless of clinical specialty, educational degree, or number of years of practice. However, data collected after a three-hour educational program showed that the program increased the clinicians' overall confidence in their ability to recognize diseases of bioterrorism $(88.6 \%)$, to address patient concerns about diseases of bioterrorism $(83.2 \%)$, to treat suspected cases $(74.6 \%)$, and to properly report suspected cases (in this instance, to the New York City Department of Health and Mental Hygiene). These data suggest that bioterrorism education is needed, and that it works.

Other studies also indicate that clinicians have both high levels of interest and important knowledge gaps with respect to bioterrorism. A survey of 614 family physicians conducted by Chen et $\mathrm{al}^{3}$ found that only $18 \%$ of respondents had any prior bioterrorism training, although 93\% reported that they thought such training was needed. Most participants 
felt more competent to deal with natural disasters and natural infectious disease outbreaks than with bioterrorism. In fact, approximately $75 \%$ considered themselves unprepared to recognize bioterrorism-related illnesses. Of particular concern was the finding that only $57 \%$ of these family physicians knew how to report cases in which bioterrorism was suspected.

Since the terrorist attacks of 2001, considerable effort has been expended to assess the capacity and capability of the public health system to prevent, detect, and respond to terrorist incidents involving weapons of mass destruction (WMDs), which are now classified as chemical, biologic, radiologic, nuclear, and explosive (CBRNE) agents. This assessment includes assessment of the skills and competencies of public health workers in general, ${ }^{4}$ as well as assessment of health professionals within public health agencies, ${ }^{5,6}$ academic health centers, ${ }^{7}$ and medical specialty practices. ${ }^{899}$ Medical schools have responded to this need by starting to integrate topics related to CBRNE agents into their curricula. Associations of health care schools have begun to develop guidance on including terrorism related information in health care schools. An example would be the Association of American Medical Colleges' convening of an expert panel on this subject and the release of the report from this group, Training Future Physicians About Weapons of Mass Destruction: Report of the Expert Panel on Bioterrorism Education for Medical Students. ${ }^{10}$ Similar reports have been issued by subspecialty societies, although their focus is more directed at the health care provider in practice. Last, many health care schools are trying to fill this knowledge gap by offering students continuing medical education (CME) courses on topics of CBRNE agents. The difficulty faced by this approach is that the majority of these courses are designed based on the assumption that participants are health care providers who have completed their training; thus, the courses are targeted at functional roles of the provider in practice. While this use of $\mathrm{CME}$ programs is an attempt to incorporate information on CBRNE agents into health care schools, it is lacking because it is not designed for the student or based on the students' knowledge level and functional role. In the end, little guidance is currently available regarding the content and teaching methods that would be most appropriate to educate health care students on emergency preparedness and CBRNE agents topics.

\section{Existing curricula}

Many of the subjects that would be in a CBRNE agents curriculum are already part of traditional curricula at schools for health professionals, including schools of medicine, dentistry, and nursing. Courses in pathophysiology, toxicology, infectious diseases, public health, emergency preparedness/disaster response, biostatistics, and epidemiology introduce concepts and topics that form the foundation for the training needed to prepare for and respond to threats from specific WMDs. Building on these familiar concepts should help to ensure that graduate health professionals are armed with the necessary knowledge and skills to become competent and prepared physicians, dentists, nurses, public health workers, and allied health practitioners. Such individuals will have the clinical knowledge and skills needed to practice effectively in the modern environment, in which the possibility of a CBRNE event has become real, not just theoretical. However, schools for health professionals will also need to equip their students with the skills to interact within multidisciplinary teams in the context of CBRNE-agents preparedness and response, including the collection and preservation of forensic evidence. A coordinated and multidisciplinary response to a terrorist attack is essential in mitigating death and disease, while maintaining public order and the fundamental elements of the health care system.

There are some existing curricula that attempt to specifically address bioterrorism issues. ${ }^{11-13}$ However, health care students are a large and diverse population, which presents a challenge to curriculum development. Furthermore, systematic and formal evaluations of these curricula have not been published, so it is not known if these various programs are meeting their goals.

To our knowledge, none of the existing curricula represent a systematic effort to prepare a large cadre of health professionals to respond to a bioterrorist or similar public health emergency through a multidisciplinary, interdisciplinary, and collaborative approach. In fact; a review of the core curricula from 25 medical schools identified only one curriculum that had even a requirement for training in bioterrorism. ${ }^{14}$ This indicates a still largely unaddressed need for training in this area.

Governmental and academic responses Several initiatives have been formed in response to the various reports identifying a need for clinical education on terrorism with CBRNE agents. Educational efforts are being led by federal and state agencies; public health departments; and schools of medicine, dentistry, nursing, and public health. Many curricula are also incorporating the recently published Centers for Disease Control and Prevention (CDC) competencies on bioterrorism.

The US government has also passed a number of Congressional acts calling for a national level of readiness that specifically addresses the need for welltrained and well-prepared health care professionals. Chief among these are the 2003 Homeland Security Bill and the Nunn-Lugar-Domenici Amendment of 1997. The recently enacted Public Health Security and Bioterrorism Response Act provides funding assistance to ensure state and local public health preparedness. $^{15}$

The CDC's Centers for Public Health Preparedness have developed Web-based training programs, conferences for the public health workforce, seminars for public safety employees, graduate-level public health courses, and medical and dental educational curricula. However, these programs have largely targeted the population of health professionals already in the practice setting. To ensure preparedness on a national level, health professionals need to be prepared to participate on an interdisciplinary level as soon as they graduate and enter the health care workforce.

\section{Objective of this article}

The current increased threats of terrorism, coupled with the above findings, clearly support the need to incorporate terrorism preparedness and response material into the curricula for every health professions school in the nation. As stated earlier, in this article, we describe a process and present a list of 
core competencies for terrorism preparedness. Competencies are defined as the knowledge, skills, and abilities necessary for the effective and efficient functioning of an organization or profession. ${ }^{16}$ The competencies we present apply to all health care professions and to medical, dental, nursing, and public health students.

\section{Development Process}

The Columbia University Bioterrorism Curriculum Development project, established in 2003, has four goals:

- Thoroughly examine the existing curricula at each school on the Health Sciences Campus to identify appropriate areas for insertion of new complementary material

- Develop learning modules based on competency
- Identify and develop core material that cuts across all disciplines

- Construct specific content to fit each discipline

Methods for instruction include lecturebased classroom courses, Internet-based distance learning, and use of a "disaster learning laboratory."

The schools participating in this process are the College of Physicians and Surgeons, the School of Oral and Dental Surgery, the School of Nursing, and the Mailman School of Public Health. These schools are located in close proximity to each other on the Health Sciences Campus of Columbia University in New York City. The activities of this project were submitted to the Columbia Health Sciences Campus IRB for review and were found to be exempt activities.
The Columbia University Health Sciences Campus Bioterrorism Curriculum Enhancement Team (henceforth known as "the curriculum team") was formed as a collaborative group to oversee the process and achieve the goals defined above. The curriculum team is composed of two members from each of the four participating schools, one of whom is a curriculum expert from that school and one of whom is an expert in bioterrorism, CBRNE agents, or disaster preparedness. Each of the curriculum team members served as the "curriculum shepherd" in their home school on the health sciences campus. That is, they shepherded the new curriculum through the curriculum committee at their schools. Additional members with expertise in informatics and administration were also included on the team. We felt that adequate representation from each school was essential to facilitate successful

List 1

\section{Terms Used to Describe the Six Levels of Proficiency Established for Core Competencies for Teaching Emergency Preparedness to Health Professions Students ${ }^{23 *}$}

Level 1. "List" $\rightarrow$ Knowledge: The ability to remember previously learned material. Knowledge represents the lowest level of learning in the cognitive domain. This skill may involve recall of a wide range of material, from specific facts to complete theories. However, all that is required is recall of the appropriate information.

Illustrative verbs: define, describe, enumerate, identify, label, list, match, name, outline, recall, recite, recollect, relate, reproduce, select, state

Level 2. "Describe" $\rightarrow$ Comprehension: The ability to grasp the meaning of material. This skill may be shown by translating material from one form to another (words or numbers), by interpreting material (explaining or summarizing), and by estimating future trends (predicting consequences or effects).

Illustrative verbs: change, construct, convert, decode, defend, define, describe, distinguish, discriminate, estimate, explain, extend, generalize, give example, illustrate, infer, paraphrase, predict, restate, rewrite, solve, summarize

Level 3. "Demonstrate" $\rightarrow$ Application: The ability to use learned material in new and concrete situations. This may include the application of such things as rules, methods, concepts, principles, laws, and theories.

Illustrative verbs: change, compute, demonstrate, develop, discover, dramatize, employ, illustrate, interpret, manipulate, modify, operate, organize, predict, prepare, produce, relate, solve, transfer, use

Level 4. "Analyze" $\rightarrow$ Investigation: The ability to break down material into its component parts so that its organizational structure may be understood. This skill may include the identification of the parts, analysis of the relationship between parts, and recognition of the organizational principles involved.

Illustrative verbs: analyze, breakdown, classify, compare, contrast, determine, deduce, diagram, differentiate, distinguish, identify, illustrate, infer, outline, point out, relate, select, separate, subdivide

Level 5. "Combine" $\rightarrow$ Synthesis: The ability to put parts together to form a new whole. This may involve the production of a unique communication (theme or speech), a plan of operations (research proposal), or a set of abstract relationships (scheme for classifying information).

Illustrative verbs: categorize, combine, compile, compose, conceive, construct, create, design, devise, establish, formulate, generate, invent, make, manage, modify, organize, originate, plan, propose, rearrange, reconstruct, relate, reorganize, revise, rewrite, set up, summarize, tell, write

Level 6. "Evaluate" $\rightarrow$ Assessment: The ability to judge the value of material (statement, novel, poem, research report) for a given purpose. The judgments are to be based on definite criteria. These may be internal criteria (organization) or external criteria (relevance to the purpose). The student may determine the criteria or be given them.

IIlustrative verbs: appraise, ascertain, choose, compare, conclude, contrast, criticize, decide, defend, describe, discriminate, explain, interpret, justify, relate, resolve, summarize, support, validate, write (a review)

* For a list of the core competencies, see List 2. Each type of health professions school (e.g., nursing) is assigned a given level of proficiency for each competency (for details, see Tables 1-4). The six levels and the competencies were developed in 2004 by experts from the four health professions schools of Columbia University. 
incorporation of the new material into the core curriculum at each school. For a list of the curriculum team members, see the acknowledgments at the end of this article.

The curriculum team was initially provided with resource materials involving four important curriculum topics in the area of bioterrorism preparedness and response: recognition, reporting, treatment, and interdisciplinary participation and response. Bioterrorism preparedness and response curricula that have already been developed for the health professions were also provided to the team as models. These included the curricula developed by the American College of Emergency Physicians, ${ }^{17}$ the International Nursing Coalition of Mass Casualty Education, ${ }^{18}$ and by Landesman for schools of public health. ${ }^{19}$

The curriculum team then closely evaluated and compared the curricula from their respective schools. It was noted that there was some material specifically related to disaster preparedness within the core curriculum at the school of nursing, but that the core curricula for the schools of medicine, dental and oral surgery, and public health had no explicit material related to disaster preparedness or bioterrorism. While disaster and bioterrorism material may not have been explicitly found in the curricula of these schools, the presumption was that some of the material was already in the curriculum but presented as part of other subjects. An example would be smallpox, which is currently presented in the infectious disease curriculum including covering

\section{List 2}

\section{Summary of the Core Competencies for Teaching Emergency Preparedness to Health Professions Students*23}

\section{Emergency Management and Preparedness}

1. Disaster Phases: List and describe the different phases of disasters.

2. Hazards Risk Assessment and Planning: Explain the concepts and describe selected methods of hazards risk assessment and all-hazards planning.

3. Response Functional Roles: Explain the concepts of and describe functional response roles for one's profession, health agencies, and community members.

4. Incident Command: Explain the concept of an incident command system and describe its functional components.

5. Integration with Emergency Management: List and describe the members of the local emergency management system and describe one's role within it.

6. Communication: Explain the concepts of risk communication and describe the procedures for reporting possible disasters.

7. Governmental Resources and Authorities: List the governmental resources and outline the regulatory issues associated with emergency management and response.

8. Preparedness Evaluation: Describe evaluation activities such as table-top drills.

\section{Terrorism and Public Health Emergency Preparedness}

1. Chemical, Biological, Radiological, Nuclear and Explosive (CBRNE) Agents: List the major classes of weapons and prevention strategies for each of them.

2. Biological: List the Category A biological agents and describe their epidemiology, associated illnesses, and treatments; list the Category B agents.

3. Chemical: List the major classes of chemical agents associated with potential terrorist activity and describe their routes of exposure, associated illnesses, and treatments.

4. Radiological/Nuclear: List the types of radiation associated with potential terrorist activity and describe their routes of exposure, associated illnesses, and treatments.

5. Personal Protective Equipment: Describe the principles of and demonstrate the ability to select appropriate personal protective equipment.

\section{Public Health Surveillance and Response Systems}

1. Principles and Practice of Surveillance: List and describe the principles and procedures of surveillance and surveillance systems.

2. Public Health Interventions: List and describe the public health interventions that are part of a response to surveillance signals.

\section{(Additional competencies for clinical personnel)}

\section{Patient Care for Disasters, Terrorism, and Pubic Health Emergencies}

1. History: Demonstrate the ability to take medical histories that identify symptoms associated with exposure to CBRNE agents.

2. Physical Examination: Demonstrate the ability to conduct physical examinations that identify signs associated with exposure to CBRNE agents.

3. Differential: Demonstrate the ability to consider exposure to CBRNE agents when establishing differential diagnoses and developing problem lists.

4. Diagnosis: Demonstrate the ability to rule out, when possible, or determine an accurate diagnosis of exposure to CBRNE agents.

5. Procedures and Laboratory Tests: Demonstrate the ability to incorporate evidence-based diagnostic procedures and laboratory studies to confirm the diagnoses and/or causative agents.

6. Pharmaceutics: Knowledge of the pharmaceutics and pharmaceuticals used to combat CBRNE agents (e.g., burn therapies, biochemical antidotes, antibiotics, vaccines)

7. Treatment: Within the scope of one's professional practice, initiate physiological and psychological interventions for treatment of biological, chemical, radiological, and mass trauma injuries.

8. Identification of incident Stress Reaction: Identify the signs and symptoms of acute or delayed critical incident stress reaction among community members or responders.

9. Treatment of incident Stress Reaction: Demonstrate familiarity with a range of resources to address acute or delayed critical incident stress reactions among community members or responders.

10. Forensics: Demonstrate the ability to recognize the need for, and to collect and preserve, forensic evidence from patients who may be victims of a CBRNE event.

\footnotetext{
* These competencies were developed in 2004 by experts from the four health professions schools of Columbia
}

University. 


\section{Table 1}

\section{Core Competency Subject Areas for Emergency Management Principles *}

\begin{tabular}{|c|c|c|c|c|}
\hline \multirow[b]{2}{*}{ Competency subject arfea } & \multicolumn{4}{|c|}{ 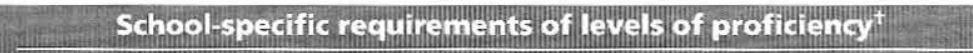 } \\
\hline & 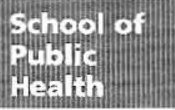 & school of & $\begin{array}{l}\text { school of } \\
\text { Bentain and } \\
\text { engingsingery }\end{array}$ & $\begin{array}{l}\text { College of } \\
\text { Physicians ant } \\
\text { Syifiognt }\end{array}$ \\
\hline 1. Phases of disaster management & Describe & Describe & Describe & Describe \\
\hline \multicolumn{5}{|l|}{ 2. Hazards risk assessment } \\
\hline a. Concept & Describe & Explain & Describe & Describe \\
\hline b. Methods & Describe & Describe & Describe & Describe \\
\hline c. Uses & Describe & Describe & Describe & Describe \\
\hline \multicolumn{5}{|l|}{ 3. Functional response roles } \\
\hline $\begin{array}{l}\text { a. Role of the citizen, community, volunteers, and various } \\
\text { health sectors and agencies in disaster planning and } \\
\text { response }\end{array}$ & Describe & Describe & Describe & Describe \\
\hline $\begin{array}{l}\text { b. Concept of disaster response functional role, and the } \\
\text { disaster response functional role for one's profession }\end{array}$ & Describe & Explain & Describe & Describe \\
\hline $\begin{array}{l}\text { c. Ability to perform basic disaster response functional } \\
\text { roles that are commonly used in one's profession }\end{array}$ & Demonstrate & Demonstrate & Demonstrate & Demonstrate \\
\hline $\begin{array}{l}\text { d. Importance of maintaining expertise and knowledge in } \\
\text { this area of practice, and participating in emergency } \\
\text { response drills }\end{array}$ & Describe & Discuss & Describe & Describe \\
\hline $\begin{array}{l}\text { e. Ability to apply knowledge and experience to new } \\
\text { situations that are posed by the emergency without } \\
\text { exceeding authority or capabilities }\end{array}$ & Describe & Demonstrate & Demonstrate & Demonstrate \\
\hline $\begin{array}{l}\text { f. Importance of personal and family preparedness and the } \\
\text { need to incorporate one's functional role into the } \\
\text { context of family and personal concerns }\end{array}$ & Describe & Explain & List & Describe \\
\hline
\end{tabular}

\section{Incident command system}

a. Concept of incident command and incident management, and how it is applied at the federal, state,

Describe

Describe

Describe

Describe local, agency and institutional level

b. Concept and function of an emergency operations center

\section{Integration with emergency management}

\begin{tabular}{|c|c|c|c|c|}
\hline $\begin{array}{l}\text { a. Processes and lines of communication in coordinated } \\
\text { multi-agency emergency response at the local, state, } \\
\text { and national level }\end{array}$ & Describe & Describe & Describe & List \\
\hline $\begin{array}{l}\text { b. Concepts of and contributions to emergency response } \\
\text { evaluation activities, exercises and scenario-based events }\end{array}$ & Describe & Describe & Describe & Describe \\
\hline $\begin{array}{l}\text { c. Social, moral, and ethical challenges that emanate from } \\
\text { disaster planning and response }\end{array}$ & Describe & Describe & Describe & Describe \\
\hline
\end{tabular}

\section{Communication}

$\begin{array}{llll}\begin{array}{l}\text { a. Risk communication principles and their application } \\ \text { during disasters }\end{array} & \text { Describe } & \text { Describe } & \text { List } \\ \begin{array}{l}\text { b. Sources to obtain accurate information during all } \\ \text { phases of a disaster or other emergency event }\end{array} & \text { Describe } & \text { Describe } & \text { List }\end{array}$

\section{Governmental resources and authority}

\begin{tabular}{|c|c|c|c|c|}
\hline $\begin{array}{l}\text { a. State and federal resources that contribute to } \\
\text { emergency management and response at the local level, } \\
\text { e.g., SNS, DMAT, MMRS }\end{array}$ & Describe & Describe & Describe & List \\
\hline b. Basic legal and regulatory issues related to emergency & Describe & Explain & Describe & Describe \\
\hline
\end{tabular}
preparedness including those pertaining to healthcare

\section{Preparedness evaluation}

Contribution of one's profession to regular emergency response drills and evaluations as a means of maintaining expertise and knowledge

* The information in this table was developed in 2004 by experts from the four health professions schools of Columbia University.

'The school-specific requirements of levels of proficiency are indicated by the verbs (e.g., "explain") under each type of school. For an explanation of how these words indicate levels of proficiency, see List 1. 


\section{Table 2}

\section{Core Competency Subject Areas for Terrorism and Public Health Emergency}

\section{Preparedness*}

\begin{tabular}{|c|c|c|c|c|}
\hline & \multicolumn{4}{|c|}{ 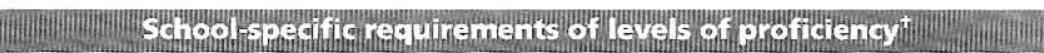 } \\
\hline gophotets subject area & 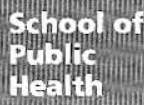 & $\begin{array}{l}\text { Sthool of } \\
\text { Nursing }\end{array}$ & $\begin{array}{l}\text { Sichool of } \\
\text { pental and } \\
\text { orginguen }\end{array}$ & 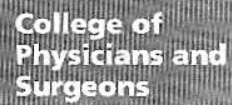 \\
\hline
\end{tabular}

1. Chemical, biologic, radiologic, nuclear, and explosive agents
a. Knowledge of the major classes of chemical biologic, radiological, nuclear and explosive agents that can be used as terrorist weapons

List List Describe Describe

\section{Biologic agents}

a. Knowledge of Category A biological agents, including epidemiology, routes of exposure, treatments, and infection control principles

\begin{tabular}{llll} 
b. Knowledge of Category B biologic agents & Describe & List & Describe \\
\hline 3. Chemical agents & & Describe \\
$\begin{array}{llll}\text { a. Knowledge of general classes of potential } \\
\text { chemical weapons, including mechanisms of }\end{array}$ & Describe & Demonstrate & Describe
\end{tabular}
chemical weapons, including mechanisms of exposure, decontamination and treatment principles and concepts of personal protection

\section{Radiological agents}

a. Types of radiation associated with potential terrorist devices, including mechanisms of distribution, effects of exposure, treatment and personal protection

\section{Personal protective equipment and decontamination}

\begin{tabular}{|c|c|c|c|c|}
\hline $\begin{array}{l}\text { a. Basic principles of selection and use of personal } \\
\text { protective equipment appropriate to a range of } \\
\text { situations typical of one's profession }\end{array}$ & Demonstrate & Demonstrate & Demonstrate & Demonstrate \\
\hline b. Principles and application of decontamination & Describe & Describe & Describe & Describe \\
\hline
\end{tabular}

* The information in this table was developed in 2004 by experts from the four health professions schools of Columbia University

"The school-specific requirements of levels of proficiency are indicated by the verbs (e.g., "explain") under each type of school. For an explanation of how these words indicate levels of proficiency, see List 1.

modes of transmission and disease presentation. But this material is presented from a historical perspective as an eradicated disease and not as a possible terrorism agent.

In determining appropriate core content for each school, the team was guided by the need to identify and develop both cross-disciplinary and school-specific material. An example of school-specific content is dental forensics, which might be required at a dental school but not at a school of public health.

The first step in developing curricula for each of the schools was to define the competencies that make up the desired outcome for the curricula. This included both core and discipline-specific competencies. The team also identified a need to provide additional clarity to the existing clinical competencies for direct patient care within the health professions.
It was soon apparent that while core competencies existed for each school, the expected level of proficiency varied among the schools. The various schools of the health sciences use different language to describe levels of proficiency, which are based on the requirements of their respective accreditation bodies. Therefore, a common nomenclature was needed as an aid to the competency development effort. The curriculum team agreed to a common set of proficiency terminology based on a modification of Bloom's educational taxonomy. ${ }^{20}$

The next phase of the project involved an exhaustive search of the medical literature via Medline, Cinhal, Embase, and other literature databases. The curriculum team sought peer-reviewed articles discussing the education of health care providers in emergency preparedness and terrorism, including articles on competency development. The search revealed that literature on competencies for emergency and terrorism preparedness was relatively sparse. The literature did contain several important articles on training programs specific to health care disciplines, but none of these presented a set of competencies that had been included in the design of training programs.

Because of the paucity of peer-reviewed literature, the search was supplemented with publications from both accreditation bodies and professional organizations. This included documents discussing competencies for medical ${ }^{10}$ and nursing schools, ${ }^{21}$ as well as some preliminary work in dental education. ${ }^{22}$ These documents were based somewhat on materials developed by federal agencies, which dealt with the roles played by the various health professions 
Table 3

Core Competency Subject Areas for Public Health Surveillance and Response*

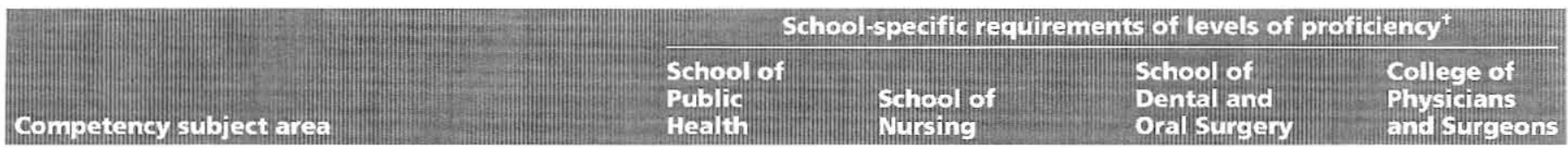

\section{Principles and practice of surveillance}

\begin{tabular}{|c|c|c|c|c|}
\hline $\begin{array}{l}\text { a. Principles of surveillance and individual reporting } \\
\text { of potential or actual emergencies that could } \\
\text { affect the health of a community }\end{array}$ & Apply & Describe & List & Describe \\
\hline $\begin{array}{l}\text { b. Procedures used to collect patient data for } \\
\text { surveillance or tracking }\end{array}$ & Apply & Demonstrate & Describe & List \\
\hline $\begin{array}{l}\text { c. Unusual clinical scenarios that may represent } \\
\text { sentinel cases of victims of an unannounced use } \\
\text { of CBRNE agents }\end{array}$ & Identify & Demonstrate & Demonstrate & Describe \\
\hline
\end{tabular}

\section{Interventions}

a. Public health interventions that are part of the response to public health emergencies such as the use of CBRNE agents ${ }^{*}$

Identify

Describe

Describe

List

* The information in this table was developed in 2004 by experts from the four health professions schools of Columbia University.

† The school-specific requirements of levels of proficiency are indicated by the verbs (e.g., "explain") under each type of school. For an explanation of how these words indicate levels of proficiency, see List 1.

* CBRNE means chemical, biologic, radiologic, nuclear, and explosive.

in emergency preparedness. However, there were no documents that defined core competencies across all health care disciplines.

The curriculum team then evaluated each of the available competencies for areas of overlap that could form the basis for a cross-disciplinary core curriculum. Those that remained were assigned to the school-specific category. Then, a second group of experts in education, emergency preparedness, terrorism, and public health were charged with developing a set of core and school-specific competencies to ensure that key areas were not overlooked. The competencies created by the experts were merged with those developed by the curriculum team.

The competencies were finalized through an iterative process that involved review, comment, and extensive editing. A proficiency level was assigned to each competency for each school, based on the agreed-on nomenclature. (The six levels are described in List 1.) The one exception was the patient care competencies which were only applied to those schools whose students will provide direct patient care. This effort was then evaluated by experts from hospital systems, universities, public health agencies, governmental agencies, and emergency management agencies, the "end-users" of our health care schools' graduates. These experts tried to determine if the competencies provided the appropriate preparation of our students to fulfill their roles as their future trainees and employees.

\section{Core Competencies}

The core competencies were placed into four categories that represent broad subject areas:

\section{- Emergency management and preparedness}

- Terrorism and public health emergency preparedness

- Public health surveillance and response

- Patient care for disasters, terrorism, and public health emergencies

Proficiency levels were assigned to each of the four health care disciplines (i.e., medicine, dentistry, nursing, and public health) involved in the project. This allows students at each school to cover a common set of core competencies, but at varying levels of expected proficiency. For example, nursing or public health students will not be expected to achieve the same level of clinical proficiency as medical students in certain clinical areas such as which pharmaceutical agent to prescribe for certain agents including contraindications and interactions with other pharmaceuticals. However, consistency in content of core competencies is key to emergency preparedness planning at all levels. For this reason, it is essential that such consistency be fostered across a broad spectrum of health care fields of education.

A summary of the content areas and the core competencies can be found in List 2 . Tables 1 through 4 outline the detailed competencies within the four broad competency categories (each table treats a different category), as well as the proficiency levels assigned by each of the four health care disciplines.

\section{Discussion}

After the terrorist events of 2001, it became apparent that the entire health care workforce needed to become better educated in the areas of terrorism and emergency preparedness. Proper preparedness also requires clear, crossdisciplinary connections between departments of public health and other health care entities. Lack of coordination across the public health and health care communities and disciplines is one of the main barriers to health care preparedness in the United States. This has been documented in both the peer-reviewed and general literature as the "silo" approach to preparedness, which hinders efforts to become better prepared. 
Table 4

Core Competency Subject Areas for Patent Care for Disasters, Terrorism, and Public Health Emergencies*

\begin{tabular}{|c|c|c|c|c|}
\hline \multirow{2}{*}{ 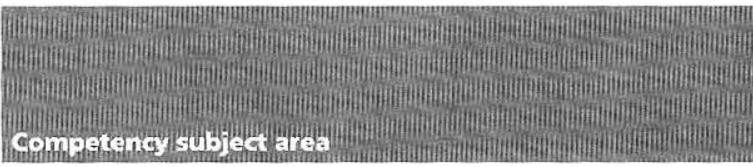 } & \multicolumn{4}{|c|}{ 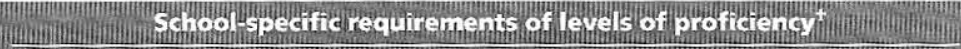 } \\
\hline & 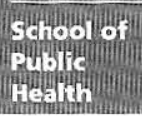 & $\begin{array}{l}\text { Sanool of } \\
\text { sursing }\end{array}$ & 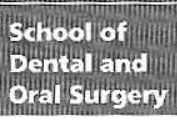 & 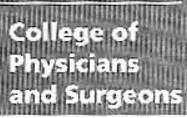 \\
\hline \multicolumn{5}{|l|}{ 1. Take medical histories that: } \\
\hline $\begin{array}{l}\text { a. Determine the absence or presence of symptoms that are } \\
\text { characteristic of exposure to CBRNE agents }{ }^{\ddagger}\end{array}$ & N/A & Demonstrate & Demonstrate & Demonstrate \\
\hline $\begin{array}{l}\text { b. Identify patients who may have psychological trauma after a } \\
\text { CBRNE event }{ }^{*}\end{array}$ & N/A & Demonstrate & Demonstrate & Demonstrate \\
\hline $\begin{array}{l}\text { c. Identify occupational and psychosocial risks for exposure to } \\
\text { potential CBRNE agents }{ }^{*}\end{array}$ & N/A & Demonstrate & Describe & Describe \\
\hline $\begin{array}{l}\text { d. Characterize exposures to potential CBRNE agents, including type } \\
\text { of agent, timing, and length of exposure } \neq\end{array}$ & N/A & Demonstrate & Describe & List \\
\hline
\end{tabular}

\section{Ability to conduct physical exams that:} characteristic of exposure to CBRNE agents ${ }^{*}$

3. Identify patterns of signs and symptoms likely to be associated with occult exposure to CBRNE agents ${ }^{\ddagger}$

4. Interpret results of the medical history, physical examination, and diagnostic evaluation to accurately diagnose CBRNE agent exposure ${ }^{t}$

\begin{tabular}{llll}
\hline $\begin{array}{l}\text { 5. Incorporate evidence-based diagnostic procedures and } \\
\text { laboratory studies to confirm the diagnoses and/or } \\
\text { causative agents }\end{array}$ & N/A & Describe & Describe \\
\hline $\begin{array}{l}\text { 6. Knowledge of signs and symptoms of acute or delayed } \\
\text { critical incident stress reaction among community } \\
\text { members or responders }\end{array}$ & N/A & Demonstrate & Describe \\
\hline $\begin{array}{l}\text { 7. Pharmaceutics and pharmaceuticals used to combat } \\
\text { CBRNE agents, e.g., burn therapies, biochemical } \\
\text { antidotes, antibiotics, vaccines }\end{array}$ & N/A & $\begin{array}{l}\text { Identify (and describe } \\
\text { range of resources to } \\
\text { address) }\end{array}$ & Describe \\
\hline
\end{tabular}

8. Consider critical aspects of treatment plans for patients

who may have been affected physically and/or

psychologically by CBRNE agents, including ${ }^{*}$ :

\begin{tabular}{|c|c|c|c|c|}
\hline a. Acute care management & N/A & $\begin{array}{l}\text { Describe and provide care } \\
\text { as appropriate to specific } \\
\text { position/role }\end{array}$ & Demonstrate & Demonstrate \\
\hline b. Long-term management & N/A & $\begin{array}{l}\text { Describe and provide care } \\
\text { as appropriate to specific } \\
\text { position/role }\end{array}$ & List & List \\
\hline c. Attention to mental health concerns & N/A & $\begin{array}{l}\text { Describe and provide care } \\
\text { as appropriate to specific } \\
\text { position/role }\end{array}$ & Describe & Demonstrate \\
\hline e. Consultation with public health authorities & N/A & $\begin{array}{l}\text { Describe and provide care } \\
\text { as appropriate to specific } \\
\text { position/role }\end{array}$ & Describe & Describe \\
\hline $\begin{array}{l}\text { f. The ability to use appropriate precautions to prevent CBRNE agent } \\
\text { exposure to other patients, care providers, and themselves (e.g., } \\
\text { isolation, decontamination, personal protective equipment, } \\
\text { appropriate waste disposal) }\end{array}$ & N/A & $\begin{array}{l}\text { Describe and provide care } \\
\text { as appropriate to specific } \\
\text { position/role }\end{array}$ & Demonstrate & Demonstrate \\
\hline
\end{tabular}

9. Recognize the need for, and collect and preserve,

N/A

Describe

Demonstrate

Describe

forensic evidence from patients who may be victims of a CBRNE event ${ }^{*}$

* The information in this table was developed in 2004 by experts from the four health professions schools of

Columbia University.

† The school-specific requirements of levels of proficiency are indicated by the verbs (e.g., "explain") under each

type of school. For an explanation of how these words indicate levels of proficiency, see List 1.

${ }^{\ddagger}$ CBRNE means chemical, biologic, radiologic, nuclear, and explosive 
Ensuring a unified and coordinated approach to preparedness requires that benchmarks and standards be consistent across health care and public health disciplines. This effort needs to be consistent over time to ensure long-term preparedness. Commonality of education and consistency of content among core competencies is essential for a unified and coordinated approach.

As stated earlier, educational initiatives have so far been focused on providing bioterrorism and emergency preparedness training to the existing health care workforce. However, recent attention has begun to focus on courses for the health care students that represent the future population of health professionals. As health professions schools prepare to educate these students, it is important to remember that the needs of students may differ from those of practitioners. In fact, we feel that there is a fundamental difference between educational competencies and occupational competencies, so that existing programs in continuing education cannot simply be applied to the academic setting. Before designing new educational programs for students, one must first define the competencies addressed by the proposed material. The project we have described above represents a first attempt to define competencies for student education in emergency and terrorism preparedness.

In addition to establishing the necessary foundation to develop emergency and terrorism preparedness curricula and creating a set of core competencies applicable to all health professions students, the curriculum team has also shown that nonclinical practitioners can, and, indeed, must be included in this process. In fact, although initially directed at dental, medical, nursing, and public health students, these competencies can easily be adapted to other health care disciplines. The primary variations would be in the assignment of proficiency levels and decisions about the need for clinical competencies.

The competencies that we have established serve as a starting point for a set of curricula that cut across health care disciplines. These competencies can help ensure that all health care graduates possess a common, core set of emergency and terrorism preparedness

competencies. However, we recognize that the fields of emergency management and bioterrorism/disaster preparedness advance on a regular basis, and these competencies must change over time as part of this advancement. In addition these competencies need to be adopted by other health professions schools. As a first step towards this goal it is important that the accreditation bodies for each of the different health professions schools review these competencies and integrate them into the requirements for accreditation of schools. At the same time health professions schools must map these competencies against their existing curriculum to determine those elements already covered and those requiring either modification or addition to the curriculum. Future efforts will also need to include the training of health professions faculty so that there will be a cadre of individuals able to teach this new material at the health professions schools.

The authors would like to thank all members of the Columbia University Health Sciences Campus Bioterrorism Curriculum Enhancement Team-which Dr. Markenson and Dr. Redlener co-chaired and for which Dr. DiMaggio served at the project director-for their help in the creation and refinement of the competencies described in this article: From Columbia University Health Sciences Campus Leadership, Gerald Fischbach, $\mathrm{PhD}, \mathrm{MD}$, vice president, and Joanna Rubenstein, PhD, DDS, associate dean. From Columbia University College of Physicians and Surgeons, Ronald Drusin, MD, professor,

Eliot Lazar, MD, MBA, associate professor, and Scott Hammer, MD, professor. From Columbia University Mailman School of Public Health: Ian Lapp, PhD, assistant dean, Robyn Gershon, DRPH, associate professor, Stephen Morse, $\mathrm{PhD}$, associate professor, Kristine Qureshi, DNSc, RN, assistant professor, and Raquel Schubert, research assistant. From the Columbia University Mailman School of Oral and Dental Surgery: Letty Moss-Salentijn, $\mathrm{PhD}$, associate dean and professor and James Fine, DMD, associate professor. From the Columbia University School of Nursing, Sarah Cook, MEd, $\mathrm{RN}$, vice dean, and Kristine Gebbie, DRPH, RN, associate professor. From the New York City Department of Health and Mental Hygiene: Isaac Weisfuse, MD, deputy commissioner. From the New York City Office of Emergency

Management: Calvin Drayton, deputy

commissioner, and Sam Benson, director.

The efforts of the authors and several of the reference documents quoted were in part funded by grant 6 T01HP01394-01-01 from the Bureau of Health Professions, Health Resources Services Administration, Department of Health and Human Services and from funding provided by The Children's Health Fund.

\section{References}

1 American Association of Critical-Care Nurses (AACN). Statement of Commitment on Mass Casualty and Bioterrorism Preparedness 〈http://www.aacn.org/ $\rangle$. Accessed 1 March 2005.

2 Gershon RR, Qureshi K, Sepkowitz K, Gurtman A, Galea S, Sherman M. Clinicians' knowledge, attitudes and concerns regarding bioterrorism after a brief education program. J Occup Environ Med. 2004;46(1):77-83.

3 Chen FM, Hickner J, Fink KS, et al. One the front lines: family physicians' preparedness for bioterrorism. J Fam Pract. 2002;51:745-50.

4 Columbia University School of Nursing Center for Health Policy. Bioterrorism and Emergency Readiness: Competencies for All Public Health Workers. Columbia University: New York, 2002.

5 Fraser MR, Fisher VS. Elements of Effective Bioterrorism Preparedness: A Planning Primer for Local Public Health Agencies. National Association of County and City Health Officials (NACCHO): Washington, DC: NACCHO, 2001.

6 Centers for Disease Control and Prevention. Biological and chemical terrorism: strategic plan for preparedness and response. MMWR Recomm Rep. 2000;48(RR-4):1-14.

7 Rubin ER, Osterweis M, Lindeman LM (eds). Emergency Preparedness: Bioterrorism and Beyond. Association of Academic Health Centers: Washington DC, 2002.

8 American College of Emergency Physicians. Final Report: Developing Objectives, Content, and Competencies for the Training of Emergency Technicians, Emergency Physicians, and Emergency Nurses to Care for Casualties Resulting from Nuclear, Biological or Chemical Incidents. Washington DC: Department of Health and Human Services, Office of Emergency Preparedness, April 2001.

9 American College of Surgeons. Disasters from Biological and Chemical TerrorismWhat Siould the Individual Surgeon Do? A Report from the Committee on Trauma 〈http://www.facs.org〉. Accessed March 2005.

10 Association of American Medical Colleges. Training Future Physicians About Weapons of Mass Destruction: Report of the Expert Panel on Bioterrorism Education for Medical Students. Washington, DC: AAMC, 2003.

11 Association of Schools of Public Health. Public Health Preparedness Resource Center 〈http://www.asph.org/phprc〉. Accessed 16 June 2003.

12 University of Minnesota School of Public Health. The 2003 Public Health Institute 〈http://www.cpheo.umn.ed/institute〉. Accessed 10 June 2003.

13 Biological and chemical terrorism: strategic plan for preparedness and response. MMWR Recomm Rep. 2000;29(RR-4):1-14.

14 Association of American Medical Colleges. Number of U.S. Medical Schools Teaching Selected Topics 2000-01 (http://services.aamc.org/currdir/section2/ LCMEHotTopics.pdf). Accessed 16 June 2003. 
15 Centers for Disease Control and Prevention. Investigation of anthrax associated with intentional exposure and interim public health guidelines. MMWR Morb Mortal Wkly Rep. 2001;50:889-93.

16 Columbia University School of Nursing Center for Health Policy. Bioterrorism and Emergency Preparedness: Competencies for All Public Health Workers. New York: Center for Health Policy, November 2002.

17 American College of Emergency Physicians. Positioning America's Emergency Health Care System to Respond to Acts of Terrorism: A Report of the Terrorism Response Task Force. American College of Emergency Physicians, October, 2002.
18 American Association of Critical-Care Nurses (AACN). Statement of Commitment on Mass Casualty and Bioterrorism Preparedness 〈http://www.aacn.org/ $\rangle$. Accessed 1 March 2005.

19 Landesman L. Disaster Preparedness in Schools of Public Health: A Curriculum for the New Century. Washington, DC: Association of Schools of Public Health, Public Health Foundation, 2001.

20 University of Mississippi. Bloom's Taxonomy Cognitive Domain. [Modification of work by Norman E. Gronlund.] /http://www.olemiss. edu/depts/educ_school/CI/docs/STAI/manual8. htm). Accessed 20 April 2004.
21 The National Health Professions Preparedness Consortium. International Nursing Coalition for Mass Casualty Education /http://www.mc.vanderbilt.edu/ nursing/coalitions/INCMCE/nhppcoverview. pdf $\rangle$. Accessed 22 June 2003 and verified unchanged 22 December 2004

22 New York University Center for Catastrophe Preparedness and Response 〈http://www.nyu.edu/ccpr〉. Accessed 25 August 2004.

23 University of Mississippi. Bloom's Taxonomy Cognitive Domain. [Modification of work by Norman E. Gronlund.] /http://www.olemiss. edu/depts/educ_school/CI/docs/STAI/ manual8.htm $\rangle$. Accessed 20 April 2004. 